\title{
The Experience of Outsourcing Transfer: Implications for Guidance and Counselling.
}

Paper accepted for publication in the British Journal of Guidance \& Counselling.

Dr. Stephanie J. Morgan* and Dr. Gillian Symon

Department of Organizational Psychology

Birkbeck College,

University of London.

Malet Street

LONDON

WC1E 7HX

*Now at Kingston University Business School

Stephanie.morgan@kingston.ac.uk

ESRC Grant No. R42200024292 


\section{The Experience of Outsourcing Transfer: Implications for Guidance and Counselling}

ABSTRACT Outsourcing can involve the forced transfer of employees to another organization. During or after the transfer they may find their jobs have changed or go through a process of downsizing. They also often have to maintain a relationship with their previous employer as they continue to work on joint projects. In this paper we review relevant research literature and identify important psychological and organizational processes involved in this process, which are of specific interest to guidance and counselling. We also present data from a longitudinal research study in which employees undergoing an outsourcing transfer discussed their experiences. A number of these employees required career counselling and some were undergoing psychological counselling to reduce depression and anxiety. In conclusion, we summarise important issues to be considered by the counsellor when advising individuals going through this process.

Keywords: Counselling, Job Insecurity, Outsourcing, Organizational Justice, Psychological Contract. 
Outsourcing is a form of change used increasingly by organizations as a method of reducing costs and enabling focus on core competencies. While it can take many forms, the focus here is on situations where employees are transferred to another organization. Although the individuals are employed by a different company, their work generally remains the same, they interact with colleagues who have remained in the original organization, and often stay on the same premises. The company to which they are transferred will be of a different style to their original employer, tending to expect more flexibility, and treating employees in a more contingent manner (Allen \& Henry, 1996). Even in professional areas, such as IT, where workers are encouraged to consider themselves as 'core' to the new organization, the cultures are often very different, with generally more demands being placed on employees for speed and a commercial attitude (Lacity \& Willcocks, 2000). Outsourcing transfers such as these are increasing in volume each year, in both the public and private sectors, in Europe and the US (Barthelemy \& Geyer, 2001; Purcell \& Purcell, 1998).

Such outsourcing transfers can be traumatic for the employees involved. Although their terms and conditions are protected by TUPE regulations (Transfer of Undertaking, Protection of Employment), the very nature of a forced termination of employment, even with a transfer to another company, can be unsettling. Although, in principle, individuals have a 'choice' - they could seek alternative employment - this is rarely a simple matter, especially for employees with many years dedicated to a career in one organization. Despite this increasing practice of outsourcing transfers, and the significant implications for those involved, limited research has been carried out on the actual experience of being outsourced (although there has been some consideration of the impact of outsourcing on commitment and job satisfaction specifically e.g. Kessler, Coyle-Shapiro \& Purcell, 1999; Logan, Faught \& Ganster, 2004). There is a pressing 
need to understand the psychological and career implications of such a practice for those most closely affected. Given the severe disruption for the individuals involved, counsellors (both career and therapeutic specialists) are likely to see an increasing number of individuals in need of guidance following outsourcing transfers; therefore an understanding of the processes involved is needed to ensure guidance is most effective.

This paper is in two parts. Firstly, we summarise the findings of the limited work conducted in the area of outsourcing and identify relevant theoretical concepts from other areas that may help explain individual reactions to outsourcing. Secondly, we present a longitudinal study of employees in the IT industry going through an outsourcing transfer. From our interviews with these individuals, we identify psychological reactions to the outsourcing process and perceived implications for careers and employment. These experiences emphasise the crucial (and often detrimental) impact outsourcing has on individuals and highlight the need for specific counselling interventions.

By reviewing relevant literature and presenting evidence from individuals' actual experiences, our aims are to highlight outsourcing as a life-changing process for the individuals involved, consider how we might explain reactions to the process and provide some indication of the issues raised for guidance and counselling.

\section{Review of Outsourcing and Related Research Literature}

In this review, we examine studies which have directly addressed the issue of outsourcing, and research in other areas which can contribute to our understanding of the process. In the latter case, we focus on research into downsizing and mergers, 
including organisational justice. [We do not discuss work stress and coping, or transition counselling, but would encourage interested readers to see Dewe (2004), and Briner, Harris \& Daniels (2004) for the former, and Brown (1995) and Saam, Wodtke \& Hains (1995) for the latter]. We do not provide an exhaustive review but rather highlight those issues of most pertinence to the outsourcing experience, and of most relevance to guidance and counselling.

\section{Outsourcing}

There has been little research which specifically explores how individuals experience the process of being outsourced. What limited research there is tends to focus on the impact of their new employment status. In the latter case, some studies of secondary workers (e.g. Allen \& Henry, 1996; Benson, 1998), indicates that work for such employees often becomes both irregular and insecure, as contracts are continually renegotiated. The process of tendering itself introduces an element of formal insecurity and contracted workers may increasingly become marginalised (Allen \& Henry, 1996).

The psychological aspects of outsourcing are generally classified as part of the 'hidden cost' of outsourcing (Barthelemy, 2001), or as emanating from a likely culture-clash (Kern \& Willcocks, 2000). Despite a focus on clear procedures for transferring employees, the emphasis for many outsourcing companies is on risk-reduction for the organisation (see Useem \& Harder, 2000 as an example of this approach). The particular difficulties experienced by employees transferred remains under-examined and poorly understood. Interestingly, some of the recommendations made by management literature could make the experience worse for those involved. Most recommend short-term contracts and selective sourcing (Baldwin, Irani \& Love, 2001; 
Lacity \& Willcocks, 2000), meaning that employees would be transferred for two or three years, and possibly in small groups, with other groups remaining in-house, or being transferred to a different organization. These factors are likely to increase anxiety, in terms of having short time-scales before uncertainty around contracts resurfaces, and increase tension and feelings of being unwanted, when some groups are singled out for transfer. The potential impact of these recommendations on employees has not been considered.

A study by Kessler, Coyle-Shapiro and Purcell (1999) is rare in focusing on employee reactions to an outsourcing transfer. They found that most respondents had a more positive view of career development with their new employer, compared to their previous employer. This is an aspect that outsourcing companies try to emphasise when managing transfers. However they also found that, perhaps due to high expectations, career prospects were not perceived as fulfilled. Other research indicates a less positive view, including difficult relations with original employer and negative long-term impact (Charara, 2004; Logan, Faught \& Ganster, 2004; Morgan, 2003). Studies in related areas demonstrate increased work-related injury and illness as a result of similar organisational changes (Mayhew, Quinlan \& Ferris, 1997).

To summarise, research in the area of outsourcing, though limited, indicates that individuals may have concerns regarding their career development, and are likely to experience general anxiety. There are likely to be ongoing feelings of insecurity, difficulties adjusting to new relationships, and potentially, adverse health consequences. We further explored some of these potential outcomes in our empirical work as outlined below. However, we can already see the potential implications for a variety of counselling interventions such as the need to advise on career choices, how to adapt to a 
new employment status, how to manage career expectations and how to cope with or alleviate anxiety.

Downsizing, Mergers, and Justice

Our understanding of outsourcing and its implications for guidance and counselling may be informed by research on related organizational change processes such as downsizing, and mergers and acquisitions. In this section, we consider what we can learn from these specific areas.

Studies of downsizing have often focused on 'survivor' reactions i.e. the psychological impact of downsizing on those who are left in the organization (e.g. Amundsen, Borgen, Jordan \& Erlebach, 2004). It has been found that survivors of downsizing experience emotional upheaval (Armstrong-Stassen, 1993), lose trust, and re-appraise their relationship with the organization (Rousseau \& Wade-Benzoni, 1995), and that there is a long-term reduction in commitment, motivation, and job satisfaction (see e.g. Allen, Freeman, Russel, Reizenstein, \& Rentz, 2001; Stjernberg \& Tillberg, 1998). De Vries \& Balazs (1997) analyse the links between downsizing and 'employability' (Iles, Forster \& Tinline, 1996). They argue that the breaking of the psychological contract and the enforcement of shorter-term, limited security relationships, go against an employee's need for connectedness and affiliation. Research on contract violations (e.g. Robinson \& Wolfe Morrison, 2000), and on the mediating role of trust in this process (Robinson, 1996) are also important in explaining survivor reactions to downsizing. Research also indicates poor long term health (Vahtera, Kivimaki, \& Pentti, 1997) and that avoidance tactics in particular may lead to physical and psychological illness 
(Hughes, 2000). Hughes recommends that therapeutic and career counselling may be helpful for both victims and survivors.

To the extent that outsourcing also involves some element of 'surviving', these processes and reactions are also of relevance to our understanding of that process. However, the question of who should be regarded as a 'survivor' of the outsourcing process is somewhat complex. As outsourcing often involves some initial element of downsizing, survivors can be described as both those who stay with the original organization and those who are outsourced (at least both groups are still in some sort of employment). On the other hand, those remaining in the organization may be regarded (or regard themselves) as more clearly 'survivors'. In addition, those individuals who are outsourced may be later 'downsized' from their new organization (this particular point emphasises the potential ongoing effects of the outsourcing process). Such individuals may experience the loss in the same way as other long drawn out downsizing processes, including increased pessimism, despair and anxiety (e.g. Gowan \& Gatewood, 1997) and a reduction in self-esteem (Kinnunen, Feldt, \& Mauno, 2003). Furthermore, as outsourcing contracts are often re-negotiated on a regular basis, there may be similar experiences to repeated downsizing, which research suggests leads to depression and health problems (Moore, Grunberg \& Greenberg, 2004).

Downsizing research has also focused on the influence of organizational justice. Expressions of resentment towards their employing organization by survivors were linked specifically to negative impressions of procedural justice (fairness of the methods or procedures - see Konovsky \& Brockner, 1993). Perceived procedural justice has also been shown to influence a range of attitudes after a merger (Lipponen, Olkkonen, \& Moilanen, 2004), and after extensive reorganization (Kernan \& Hanges, 
2002). There is a repeated finding that good attention to procedural justice can increase perceptions of fairness even if the outcomes of change are unfavourable (see Brockner, 2002 for a discussion). Consequently, we argue that perceptions of procedural justice specifically are important to the experience and outcomes of outsourcing. Justice in outsourcing may be particularly poor as senior managers tend to assume that employees are no longer their problem, as they have handed over responsibility to another organization (Lacity \& Willcocks, 2000). If we assume that, at least initially, employees will view being forcibly transferred to another organization as unfair, proper attention to procedural justice may reduce their perceptions of unfairness.

Because those transferred have not lost their jobs, but are forced to join another company, research into mergers and acquisitions may also be useful to aid our understanding. Negative employee reactions are frequently claimed to be responsible for unsuccessful mergers (Buono \& Bowditch, 1989; Cartwright \& Cooper, 1994). Although unequivocal findings are few, it seems logical that the widespread disruption and lack of control may lead to job insecurity and anxiety. However, usually in mergers and acquisitions only one company remains as a focal organization, and the long term impact may therefore be very different in outsourcing, where a continual relationship needs to be maintained with the previous employer. Merger literature therefore, may be of use in aiding our understanding of the insecurity and anxieties felt, but research specific to outsourcing is needed to assess the impact of continuing long term relationships.

Literature on both downsizing and mergers often uses a bereavement metaphor and focuses on reaction stages. Many draw on the Kubler-Ross (1969) psychological model of bereavement (feelings of disbelief and denial, anger, emotional bargaining and 
depression, followed by acceptance - readers may wish to see Cartwright \& Cooper, 1994, for a discussion specifically related to mergers). These models suggest employees may become fixated at an early stage, leading to unproductive behaviour. Whilst there are some problems with stage models, in particular the tendency to focus on 'states' rather than processes, working with the client towards the acceptance of the emotional aspects of the change process may be useful, particularly where uncertainty and loss of control are experienced, such as in outsourcing (see Donaldson-Feilder \& Bond, 2004).

Not surprisingly downsizing, mergers and outsourcing transitions are likely to lead to strong feelings of job insecurity. This has been linked to: reduced psychological wellbeing and health (Ferrie, Shipley, Marmot, Stansfeld \& Smith, 1998a), poor relationships with colleagues and superiors (Kinnunen, Mauno, Natti \& Happonen, 2000); and low self-esteem (Kinnunen, Feldt \& Mauno, 2003). Research on the effects of market testing (where public sector departments are tested and prepared for transfer to the private sector - a precursor to outsourcing) suggests such long term threats to employment security have adverse consequences for health status (Ferrie et.al., 1998b). However people do vary in the level of job insecurity they feel. Personal situation, including level of economic security, is a key element of job insecurity (Greenhalgh \& Rosenblatt, 1984; Jacobson \& Hartley, 1991). Thus counsellors need to be aware that this is a potential issue but that other factors will also influence employee reactions.

The literature on downsizing and mergers is therefore generally relevant to outsourcing as such transfers are likely to have elements of the insecurity and uncertainty found in these change processes. Fugate, Kinicki \& Scheck (2002) argue that the uncontrollable nature of these forms of organizational change inhibits the use of active coping. The 
analysis presented here seeks to clarify the implications of outsourcing and suggest how counsellors can help clients to work through these effects of uncertainty.

\section{Summary}

The above review indicates various theoretical concepts and empirical findings that might inform our understanding of the outsourcing process. The outsourcing literature itself suggests professional employees may have unmet expectations regarding career prospects, and that employees are likely to feel increased job insecurity and possibly increased health problems. The downsizing literature also supports this and indicates the long term negative impact of insecurity and uncertainty for both survivors and victims. Research on organizational justice suggests employees may feel resentment if they experience the enforced nature of the change as unfair. These findings already raise potential issues for counselling in relation to outsourcing. However in outsourcing two companies remain involved, and transferred employees have an ongoing relationship with old colleagues; research specific to outsourcing is therefore needed to assess differences and gain insight into the experience. Reports from an actual outsourcing transfer will enable us to assess how well the literature does reflect the individual experience, and gain more insight into the nature of the worries and concerns that may be expressed during guidance.

\section{Longitudinal Interview Study of Individuals Undergoing Outsourcing}

The research involved depth interviews (Kvale, 1996) over two time-frames. In the first part of the study, the first author interviewed 33 employees who had been recently transferred (between 2 and 6 months) from the I.T. Departments of a range of 
organisations to a particular systems house that would then be supplying I.T. services to their original employer. Participants came from different parts of the country, which reduced the potential bias towards employees living in areas where jobs were plentiful. This systems house had clear policies and procedures for managing transfers, and a great deal of experience in the process. Of the original participants 18 were available to take part in a second round of interviews 6 to 8 months later.

The interviews lasted for approximately one and a half hours each and all were taped and transcribed verbatim. Ethical guidelines were adhered to at all times, with all participants being fully briefed, assured full anonymity and offered the right to withdraw at any time. Questions in the first interview focused on their experience of the outsourcing transfer, and their relationships with the two organisations. In the second interview, participants were asked about their experiences and relationships since the first interview. At the end of this interview, they were presented with the interpretation of the first interview for comment. This process was not seen, in this case, as necessarily validation of the findings (given issues around whose interpretation can be considered 'accurate') but was useful in gaining additional information to enable reconsideration of our perception of the initial data (Bloor, 1997). At all times participants were allowed to develop the discussion into areas they felt important, rather than adhering to strict questioning. All questions and answers were fully transcribed.

Analysis was based on a hermeneutic approach. This interpretive form of analysis stipulates that the meaning of a part can only be understood if it is related to the whole (see Alvesson \& Skoldberg, 2000). In terms of data analysis, this requires use of the hermeneutic circle (Martin \& Sugarman, 2001); continual immersion in both the parts and the whole of the text (interview transcript) to develop a deep understanding. 
Specific coding of the transcripts is avoided until the researcher believes a depth of understanding has developed. Concepts from Heidegger's existential philosophy (Heidegger, 1962; Skoldberg, 1998) were used to help guide the interpretation. This approach alerts the researcher to how context, time, anxiety and concern influence participants' own understanding of their experience. This was chosen to enhance our ability to focus on individual experience over time.

Transcripts were analysed by repeated readings of each in turn, allowing understanding of the whole of the transcript to inform our interpretation of specific extracts. After all of the transcripts had been analysed in this way, the first author returned to each transcript individually and made further notes regarding similarities and differences across the sample. A similar process was used for the second set of interviews. Initially, the second interviews were analysed in isolation from the first, then a further set of analyses were carried out to identify changes over time, firstly across individuals, and then the entire sample. As Heidegger's hermeneutics is classed as alethic (Packer \& Addison, 1989) rather than attempting to bracket (withhold) existing knowledge, it was accepted that this knowledge, including the literature cited in earlier sections, was likely to influence the analysis. [For a discussion of this distinction and hermeneutical analysis see Alvesson \& Skoldberg, 2000; see also McAuley, 2004]. However this approach also allows new themes and concepts to emerge from the analysis, as the interpreter remains open to additional findings.

A number of themes were developed and a range of notes and diagrams, including timecharts were also drawn up with generalised notes on the experiences discussed, linked to notes regarding individual context. For the purposes of this paper we will concentrate on themes that were particularly related to concerns and anxieties during the transfer 
process, as these are most likely to be of significance to guidance and counselling. The transfer process was primarily discussed in the first interviews, as this is when the experience will have been most recent. However the same themes were also to some extent discussed by participants in the second interviews. Where changes are evident from the second interviews, we have highlighted the nature of these. Whilst there was some variation in discussions between individuals and over time, very few were extremely positive regarding the transfer.

The original company (which consists of a number of organizations) is referred to as 'Oldco' and the new employing company to whom participants have been transferred as 'Newco'. All quotes reproduced in the text are followed by a unique identifying code which indicates the participant's number, whether it was their first or second interview, whether their original employer was in the public or private sector, and whether they are managers or line staff (e.g. 11-1, public/staff indicates participant number 11, first interview, originally employed in the public sector, staff member).

Below, we consider the participants' discussions of the transfer process, highlighting how distinct aspects of the past, present and future are used to help make sense of their experience. In particular we highlight the following: explaining the past; feelings of injustice and blame; relationships with colleagues; emotions and job insecurity; concerns regarding contract re-negotiations; and finally their views on the future. In the space available we have selected potentially interesting issues which were discussed by a number of participants. These are examples from a wider range of similar discussions, chosen because we felt they represented clearly some issues found generally across the transcripts. For simplicity we have reduced our discussion of contradictions within and between accounts and focused rather on general perceptions. We are not suggesting that 
all outsourced employees will highlight the same issues, with such a small sample generalisations cannot be made, however we believe that these illustrations will be of benefit to counsellors in providing some insight into some of the issues involved in outsourcing transfers.

\section{Explaining the past}

Participants made sense of the past by suggesting that the situation at Oldco (whichever Oldco it was) had gone downhill anyway. They were able to accept the change more positively because they no longer enjoyed working there: the atmosphere had changed, the organization was not the same, they needed a change. The organization is referred to as 'mentally dead' (9-1, public/staff) or the culture had changed 'from people to money' (8-1, public/staff). Many said they no longer felt they belonged to the organization, that they didn't fit in any more. This seemed to help them find their way through the process 'I knew I needed to leave', (14-1, public/staff) and helped them look upon the move in a more positive way.

Some participants spoke as if they could not understand why outsourcing was happening to them. Some suggested that length of service 'obviously means nothing really' (6-1, public/mgr). Individuals showed surprise that they were ever involved in such a process - 'I'm supposed to be one of the good guys' (13-1, public/mgr), suggesting denial. For some the idea that it was nothing personal was very important 'you are just a cog in the wheel' or 'I was just in the wrong seat at the wrong time' (6-1, public/mgr). Although the recognition that it was not personal helped in some ways (the participants are not lacking in some way in themselves, it's just the way the system works), it also generated ill-feeling. The idea that 'you are just a body, a number, you 
are going whether you want to or not' (9-1, public/staff) led to discussions about the uncaring attitudes of those responsible for the decisions.

\section{Injustice and blame}

There were many discussions regarding how badly the outsourcing process was managed, with poor communication and an apparent lack of understanding by management. This was particularly the case for those in the public sector who had experienced rumours of change for years, in the form of 'market testing' and then later very long drawn out discussions about possible outsourcing. In these cases the loss of trust was widespread:

' $y$ 'know the way they were treating us and the way they were sort of y'know saying what was happening, you just didn't trust them to be honest, we just thought there was a hidden agenda' (11-1, public/staff)

The perceptions of poor treatment also seemed to help some people disassociate themselves from the previous organization. Things had got so bad that 'I didn't want to be left at the Oldco at that stage, I was quite happy to be outsourced' (19-1,

public/staff). Some participants said they felt sad, that they were aware that it was poor management that made things so difficult 'it doesn't need to be that painful' (17-1, private/staff).

As with many forms of organizational change, the participants emphasised feelings of low control: 
'What I particularly didn't like was that I felt out of control, I didn't feel as I had any say in the matter, and I didn't like that, I like to feel I have at least, some sort of say, in some direction, with my career, and, some choice at least, there was no choice, erm, and that was quite worrying,' (33-1, private/staff)

Generally the original organization was blamed for feelings of low control and misunderstandings. Whilst it may be useful to be able to blame the organization, this may not be helpful when a long term relationship is still required.

\section{Relationships with Colleagues}

As the old employer becomes a 'client' and the original work continues, employees find themselves meeting regularly with those who remain at Oldco. The old ties are maintained by this continued contact, and some suggested that this makes it more difficult for them to bond with their new employer:

'and that's another thing on the work side, the ((Oldco)) line manager that these guys work with wont let go, he's still, deals directly with them on the 'phone, which is not, not good. What it does it erm, it continues the Oldco culture, continues the Oldco culture and won't let the Newco culture move in'. (9-1, public/staff)

Difficulties with relationships were explicitly discussed by participants. Many spoke of the problems of having to explain to old colleagues that they now had to charge for work: some stated they enjoyed this, others found it extremely difficult. Some expressed the conflict clearly, even using the term 'schizophrenic' (12-1, public/staff). There was 
some variation by the second interviews, with some participants suggesting they understood this role better. However others suggested that emotions were re-ignited whenever they had to meet with old colleagues, even after changing buildings. The idea that it was difficult to adjust to the new culture, as highlighted in the above illustration, was also expressed many times. Some suggested that the greatest problem was their physical distance from the new employer. This did not seem to improve over time.

\section{Emotions and Job Insecurity}

There was much talk of anger, and indeed anger that was sustained over a long period of time - 'it grew and grew' (8-1, public/staff). Some of this was aimed at the organization generally and was often linked to a perceived lack of fairness. For some participants, this may have been a way of understanding why they felt so hurt.

The feedback between emotions and behaviour was particularly interesting in one case. The participant discussed her anger, and stated that one day she realised the entry door banging loudly behind her every morning mirrored her feelings. After that she took conscious pleasure in hearing the bang. It is possible that because she was unable to express her anger at work, the outlet was transferred to the door.

Another participant had been talking about the reasons the organization had mooted for the decision, which he agreed were logical, but:

'It was, basically I was okay with the idea, but it was all the mucking about, changing, really, really just, it just strips you emotionally really'. (10-1, public/staff) 
Feeling as if you were 'like the little kid who didn't get to be on the team, you weren't chosen' (9-1, public/staff) is likely to impact upon their future relationships. Many said they would never forget that feeling - 'it is something that is burnt in my mind' (28-1, private/staff). This is despite the fact that for many participants, particularly those in the public sector, job security did not seem to be a concern. When asked how he felt, this manager had to pause before he could articulate:

'hmm, erm, ..... erm, I think, I think most of the issues, were rather emotional than worry. So it was, a definite feeling that erm, that and I suppose being where I was as the head of the group,' (13-1, public/mgr)

It is interesting that worry here is separated from emotions. This suggests that the time was emotional despite not being worried for his job. It also highlights how the managers tended to feel a deeper responsibility, because of their relationships with staff. Job insecurity did seem to be an issue for some, although not always immediately expressed. Most had been assured redundancies would not be compulsory, and the IT job market at that time was still buoyant, yet there were discussions of worry. Interestingly, some seemed less secure by the second interviews, due to increased discussion of contract changes.

\section{Contract re-negotiations}

Awareness of the changes in contract and the possibility of further contract switches increased in the second interviews, perhaps leading to an increase in concern. For 
example, this manager discussed openly the new wave of anxiety contract discussions had led to:

'Newco would have gone its way and Oldco would have got its way and the staff would have gone whichever way their work went, so, yeah it did concern them.' (5-2, public/manager)

In outsourcing, employees are often kept on a form of 'mirror' contract that remains similar to their previous contact, and possibly gives a false sense of security. Some suggested that if they could remain on this old style contract they would have fewer worries:

'if I was standard I would feel very worried, I mean, you are with Newco and that's it and if another, if they pull out and somebody else comes in, will they want you?' (14-1, public/staff)

These contract discussions increased during second interviews and indicated a continual feeling of low control. Individuals may be in need of an ongoing programme of guidance and counselling in these circumstances, which we will outline during the discussion. None of the sample were offered counselling with the exception of those undergoing treatment. Some had anticipated assistance from HR, but indicated that HR were only interested in contract and payroll discussions.

\section{Looking to the future?}


Many of the participants discussed how they felt differently about work in general and about their chosen career since experiencing the transfer. For example:

'What it does do is it gets your perspective, it gives you a totally different perspective on employment. You, instead of just something, before it comes to you, you, sink all this emotional and psychological stuff into a job and then in the end, when you've been shunted about like a number you realise, you are just a number...' (9-1, public/staff)

There were concerns around the likelihood of a possible future career as a 'core' employee. Some felt they were not prepared to become as mobile and flexible as a systems house might wish. A few participants suggested that they were too old, indicating that if they were younger they might 'relish the fact that Newco had taken over' (29-1, private/staff/).

A vicious cycle is indicated where anxious individuals lacked the confidence to apply for work, giving an even lower feeling of control:

'Erm, unfortunately I don't feel the courage to go and do it at the moment, because I am back on, well, I am on anti-depressants.' (10-2, public/staff)

Others also discussed either their own illness (two other participants were still on medication at the second interview) or suggested that colleagues had suffered. However most highlighted the complexity of these matters, indicating that individual and beyondwork issues could be influencing the situation. 
To summarise, many participants felt that their relationship with their old organisation had worsened, and that the transfer was badly managed. Emotions were openly discussed, even amongst those for whom job insecurity was less of a worry. There was a great deal of anxiety regarding their future roles. For some, the experience changed their view of work altogether. Ongoing relationships and changing contracts created difficulties in achieving closure.

The literature highlighted at the beginning of this paper does appear relevant to the issues discussed by our research participants. The discussions illustrated here support the idea that short contracts may be more problematic for employees. There was evidence, particularly from the second interviews, of an ongoing feeling of insecurity, although for some this could be described more as general anxiety. A sense of injustice was clearly felt: a perceived lack of communication and related low trust are indicators of poor procedural justice. These findings support the research described earlier, and suggest that a focus on justice perceptions may be useful for researchers and practitioners. The concept of employability was somewhat resisted, concerns regarding future career were particularly evident in the older participants. There were a number of expressions of resentment, as found in the justice literature (Konovsky \& Brockner, 1993). There was evidence of disbelief and denial, anger, emotional bargaining and depression, as indicated by the Kubler-Ross (1969) model, as outlined in earlier sections. The anxiety felt (whether linked to job insecurity or not) did seem to lead to health problems for some participants. Those on medication had all been involved in a long drawn-out market testing exercise, which supports the view of Ferrie et al. (1998b) that these processes can have adverse health consequences. The key differences in outsourcing, of ongoing relationships and a lack of understanding of outsourcing itself, 
support our view that interventions may specifically need to take these issues into account.

\section{Implications for Counselling and Guidance}

Throughout the foregoing literature review and report of empirical work, we have drawn attention to potential implications for career and therapeutic forms of counselling and guidance. Although only a few explicitly suggested guidance would have been helpful, some were receiving therapeutic help and in our view many would have benefited from career guidance. This article is a preliminary raising of the issues which are of relevance to all sorts of different counselling roles (from HR advice to therapeutic counselling) but would need to be developed further by these different kinds of practitioners for their specific needs. Here we draw the implications together and suggest how counselling and guidance may offer help to those experiencing an outsourcing process.

Those who seek help after an outsourcing transfer are likely to have experienced a drawn-out period of anxiety, self-doubt, and emotional turmoil. It would be wrong to assume that because (at least initially) their job was not at risk, they were not under stress. Guidance may need to vary depending on how far through the process the client is at the time. Those who have been recently transferred may still be experiencing the grief and anger evidenced in the interviews presented here. The counsellor can help work through these emotions through empathy and active listening, and understanding of the situation, in a similar way to outplacement counselling (Aquilanti \& Leroux, 1999). Alternatively individual sessions or group workshops in which they are able to discuss and validate emotional reactions have been shown to be helpful (see Amundson, 
et al. 2004). Later on concerns may have switched to considerations of career or skills development, although some may still need to work through their initial feelings of resentment. If contract re-negotiations have started there may be concerns regarding repetition of bad experiences, or increased feelings of job insecurity.

There should be consideration of the specific difficulties of an outsourcing transfer, including the recurrent contract negotiations, and the ongoing (and often difficult) relationships with old colleagues. Insufficient research has been carried out on the experience of multiple transfers, but studies of multiple downsizing processes suggests people do not become adjusted to the experience (Moore et al. 2004). Counsellors may be able to play a role in helping improve communications if their client is still involved with the organization. It may be helpful to work on discussing value shifts with the client and if necessary enable them to create a new identity in the workplace, and hopefully be more proactive in their job search or career development. Individuals may feel a need to talk through their feelings of injustice with a counsellor (Aquilanti \& Leroux, 1999). However, such feelings may be ameliorated somewhat by perceptions of a justly executed process. Such findings imply that any counselling intervention should pay particular attention to the clients' view of the transfer process and how this was handled, as potentially colouring their experience of outsourcing. Part of a just process may be the deployment of counsellors by the organization - employers who bring-in counsellors may be viewed as behaving in a more 'just' manner. On a positive front, some of those interviewed suggested that the outsourcing process had given them time to consider their future and take actions, including training, towards developing a different career. An emphasis on potential career growth may be helpful (Latak \& Dozier, 1986). 


\section{Conclusions}

Whilst this is a small study, it could be argued that the experiences discussed in these interviews are likely to be transferable to similar outsourcing situations (Lincoln \& Guba, 1986). Further research will be needed to assess the likely prevalence of these findings; however we believe they offer insight to the outsourcing experience. The consideration of changes over time reveals that some employees may feel increased anxiety. The depth of the discussions are a strength as many participants were able to talk about their experiences for longer than they had been allowed to before, increasing the likelihood of gaining insightful reflections (Mishler, 1986) - some commented on how useful they found this. The sample consisted of IT professionals, but it is likely that the contexts of forced transfers will be similar for a range of situations. The study also concentrated on those who had been transferred, it is possible that those left behind with the original employer experienced similar (or very different) concerns. However, it is hoped that this article will enable counsellors to better understand the potential anxieties clients have experienced, and work through the nuances of the outsourcing process.

This paper is an important first step in understanding the actual experience of being outsourced. The depth interviews and intensive analysis allow us to see some of the concerns felt by staff and managers involved. The focus here has been on perceptions of the initial anxiety felt during the process, but with some indication of the long-term nature of the experience. Often employees have difficulty understanding their new situation, the contingent nature is often only fully understood when contract renegotiations begin. The continual need to liaise with old colleagues from the original company may make closure difficult. However, the transfer to the new organization 
may give employees time to adjust to change and assess their strengths and weaknesses.

In terms of counselling and guidance, the most important aspect is to be aware of the similarities and differences between outsourcing transfers and other forms of organizational change. 


\section{References}

Allen, J. \& Henry, N. (1996). Fragments of industry and employment: contract service work and the shift towards precarious employment. In R. Crompton, D. Gallie, \& K. Purcell, (Eds), Changing Forms of Employment. London: Routledge.

Allen, T. D. Freeman, D. M. Russel, J. E. A. Reizenstein, R. C. \& Rentz, J. O. (2001). Survivor reactions to organizational downsizing: does time ease the pain? Journal of Occupational and Organizational Psychology, 74(2), 145-164.

Alvesson, M. \& Skoldberg, K. (2000). Reflexive Methodology: New Vistas for Qualitative Research. London: Sage.

Amundson, N.E. Borgen, W.A. Jordan, S. \& Erlebach, A.C. (2004). Survivors of downsizing: helpful and hindering experiences. The Career Development Quarterly, 52, 256-265.

Armstrong-STASSEN, M. (1993). Survivors' reactions to a workforce reduction: a comparison of blue-collar workers and their supervisors. Canadian Journal of Administrative Sciences, 10(4), 334-343.

Aquilanti, T.M. \& Leroux, J. (1999). An integrated model of outplacement counseling. Journal of Employment Counseling, 36, 177-198.

Baldwin, L. P. Irani, Z. \& Love, P. E. D. (2001). Outsourcing information systems: drawing lessons from a banking case study. European Journal of Information Systems, 10, 15-24.

Barthelemy, J. (2001). The hidden costs of IT outsourcing. MIT Sloan Management Review, Spring, 60-69.

Barthelemy, J. \& Geyer, D. (2001). IT Outsourcing: evidence from France and Germany. European Management Journal, 19(2), 195-202.

Benson, J. (1998). Dual commitment: contract workers in Australian manufacturing 
enterprises. Journal of Management Studies, 35(3), 355-375.

BLoor, M. (1997). Techniques of validation in qualitative research: a critical commentary. In G. M. R. Dingwall (Ed), Context and Method in Qualitative Research. London: Sage.

Briner, R. Harris, C. \& Daniels, K. (2004). How do work stress and coping work? toward a fundamental theoretical reappraisal. British Journal of Guidance \& Counselling, 32, 223-234.

BRoCKNER, J. (2002). Making sense of procedural fairness: how high procedural fairness can reduce or heighten the influence of outcome favorability. The Academy of Management Review, 27(1), 58-76.

Brown, D. (1995). A values based approach to facilitating career transitions. The Career Development Quarterly, 44, 4-11.

Buono, A. F. \& Bowditch, J. L. (1989). The Human Side of Mergers and Acquisitions. Jossey Bass.

Cartwright, S. \& Cooper, L. C. (1994). The human effects of mergers and acquisitions. In C. L. Cooper and D.M. Rousseau (Eds). Trends in Organizational Behavior, John Wiley \& Sons Ltd.

Charara, J. (2004). The Impact of Outsourcing on Employees: A Guide to Organisations. Lulu (available in paperback via website or download) http://ww.lulu.com/content/66236.

Cohen-CARASh, Y. \& SPECTOR, P.E. (2001). The role of justice in organizations: a metaanalysis. Organizational Behavior and Human Decision Processes, 86, 278-324.

Dewe, P. (2004) Work stress and coping: theory, research and practice. British Journal of Guidance \& Counselling, 32, 140-151.

De Vries, M. F. R. \& Balazs, K. (1997). The downside of downsizing. Human Relations, 50(1), 11-50. 
Donaldson-Feilder, E.J. \& Bond, F.W. (2004). The relative importance of psychological acceptance and emotional intelligence to workplace well-being. British Journal of Guidance \& Counselling. 32, 187-202.

Ferrie, J.E. Shipley, M.J. Marmot, M.G. Stansfeld, S. \& Smith, G.D. (1998a). An uncertain future: the health effects of threats to employment security in whitecollar men and women. American Journal of Public Health, 88, 1030-1049.

Ferrie, J.E. Shipley, M.J. Marmot, M.G. Stansfeld, S. \& Smith, G.D. (1998b). The health effects of major organizational change and job insecurity. Social Science \& Medicine, 46, 243-254.

Fugate, M. Kinicki, A.J. \& Scheck, C.L. (2002). Coping with an organizational merger over four stages. Personnel Psychology. 55, 905-929.

Gowan, M.A. \& Gatewood, R.D. (1997). A model of response to the stress of involuntary job loss. Human Resource Management Review, 7(3), 277-297.

Greenhalgh, L. \& Rosenblatt, Z. (1984). Job insecurity: toward conceptual clarity. Academy of Management Review, 9(3), 438-448.

Heidegger, M. (1962). Being and Time, John Macquarrie \& Edward Robinson, translator, Oxford: Blackwell.

Hughes, J.L. (2000). Avoidance of emotional pain during downsizing in a public agency. Consulting Psychology Journal: Practice and Research, 52, 256-268.

Iles, P. Forster, A. \& Tinline, G. (1996). The changing relationships between work commitment, personal flexibility and employability. Journal of Managerial Psychology, 11(8), 18-34.

Jacobson, D. \& Hartley, J. (1991). Mapping the context. In J. Hartley, (Ed). Job Insecurity: Coping With Jobs at Risk. London: Sage.

Kern, T. \& Willcocks, L. (2000). Exploring information technology outsourcing relationships: theory and practice. Strategic Information Systems, 9, 321-350. 
Kernan, M.C. \& Hanges, P.J. (2002). Survivor reactions to reorganization: antecedents and consequences of procedural, interpersonal, and informational justice. Journal of Applied Psychology. 87, 916-936.

Kessler, I. Coyle-Shapiro, J. \& Purcell, J. (1999). Outsourcing and the employee perspective. Human Resource Management Journal, 9(2), 5-19.

Kinnunen, U. Feldt, T. \& Mauno, S. (2003). Job insecurity and self-esteem: evidence from cross-lagged relations in a 1-year longitudinal sample. Personality and Individual Differences, 35, 617-632.

Kinnunen, U. Mauno, S. Natti, J. \& Happonen, M. (2000). Organizational antecedents and outcomes of job insecurity: a longitudinal study in three organizations in Finland. Journal of Organizational Behavior, 21, 443-459.

Konovsky, M. A. \& Brockner, J. (1993). Managing victim and survivor layoff reactions: a procedural justice perspective. In R. Cropanzano, (Ed), Justice in the workplace: Approaching Fairness in Human Resource Management, Lawrence Hillsdale, New Jersey: Erlbaum Associates.

Kubler-Ross, E. (1969). On Death and Dying. MacMillan, New York.

Kvale, S. (1996). InterViews: An Introduction to Qualitative Research Interviewing. Thousand Oaks: Sage Publications Inc.

Lacity, M. C. \& Willcocks, L. P. (2000). Relationships in IT outsourcing: a stakeholder perspective. In R. W. Zmud, (Ed), Framing the Domains of I.T. Management, Projecting the Future, Through the Past. Cincinatti: Pinnaflex Educational Resources.

Latak, J.C. \& Dozier, J.B. (1986). After the axe falls: job loss as a career transition. Academy of Management Review 11, 375-392.

Lincoln, Y. \& Guba, E. (1986). Naturalistic Inquiry. Beverley Hills, CA: Sage. 
Lipponen, J. Olkkonen, M.E. \& Moilanen, M. (2004). Perceived procedural justice and employee responses to an organizational merger. European Journal of Work and Organizational Psychology, 13, 391-413.

Logan, M.S. Faught, K. \& Ganster, D.C. (2004). Outsourcing a satisfied and committed workforce: a trucking industry case study. International Journal of Human Resource Management, 15, 147-162.

Martin, J. \& SugARMAn, J. (2001). Interpreting human kinds: Beginnings of a hermeneutic psychology. Theory \& Psychology, 11(2), 193-207.

Mayhew, C. Quinlan, M. \& Ferris, R. (1997). The effects of subcontracting/outsourcing on occupational health and safety: Survey evidence from four Australian industries. Safety Science, 25,163-178.

Mcauley, J. (2004). Hermeneutic understanding. In C.Cassell \& G. Symon (Eds), Essential Guide to Qualitative Methods in Organizational Research. Sage: London.

Mishler, E. G. (1986). Research Interviewing: Context and Narrative. Cambridge, Mass: Harvard University Press,.

Moore, S. Grunberg, L. \& Greenber, G. E. (2004). Repeated downsizing contact: the effects of similar and dissimilar layoff experiences on work and well-being outcomes. Journal of Occupational Health Psychology, 9, 247-257.

Morgan, S. (2003). Organizational Attachments in IT Outsourcing. Unpublished PhD Thesis. University of London.

PACKer, M. J. \& AdDISON, R. B. (1989). Entering the Circle: Hermeneutic Investigation in Psychology. Albany NT: SUNY Press.

Purcell, K. \& Purcell, J. (1998). In-sourcing, outsourcing, and the growth of contingent labour as evidence of flexible employment strategies. European Journal of Work and Organizational Psychology, 7(1), 39-59. 
Robinson, S. L. (1996). Trust and breach of the psychological contract. Administrative Science Quarterly, 41(December), 574-599.

Robinson, S. L. \& Wolfe Morrison, E. (2000). The development of psychological contract breach and violation: a longitudinal study. Journal of Organizational Behavior, 21, 525-546.

Rousseau, D. M. \& Wade-Benzoni, K. A. (1995). Changing individual-organization attachments: a two way street. In A. Howard, (Ed), The Changing Nature of Work. San Fransisco: Jossey-Bass.

SaAm, R.H. WodtKe, K.H. \& Hains, A.A. (1995). A cognitive stress reduction program for recently unemployed managers. The Career Development Quarterly, 44, 4351.

SkOLDBERG, K. (1998). Heidegger and organization: notes towards a new research programme. Scandinavian Journal of Management, 14(1/2), 77-102.

Stjernberg, T. \& Tillberg, U. (1998). When structure and meaning break down - taking responsibility in downsizing. European Journal of Work and Organizational Psychology, 7(3), 355-371.

UsEem, M. \& HARDER, J. (2000). Leading laterally in company outsourcing. Sloan Management Review, Winter, 25-36.

Vahtera, J. Kivimaki, M. \& Pentti, J. (1997). Effect of organisational downsizing on health of employees. The Lancet, 350, October 18, 1124-1128. 